\title{
Low birth weight and the delay on the eruption of deciduous teething in children
}

Cristiane Ribeiro da Silva Castro 1

iD https://orcid.org/0000-0002-2480-4025

Maria Beatriz Barreto de Sousa Cabral 2

iD https://orcid.org/0000-0001-5150-2033

Eduardo Luiz Andrade Mota 3

iD https://orcid.org/0000-0001-7819-0084

Maria Cristina Teixeira Cangussu 4

iD https://orcid.org/0000-0001-9295-9486

Maria Isabel Pereira Vianna 5

iD https://orcid.org/0000-0003-4478-6941

1 Secretaria de Saúde do Estado da Bahia. Salvador, BA, Brasil.

2,4,5 Faculdade de Odontologia da Bahia. Rua Araújo Pinho, 6. Andar, 62 Canela. Salvador, BA, Brasil. CEP: 41110-150. Email: isabel@ufba.br

3 Instituto de Saúde Coletiva. Universidade Federal da Bahia. Salvador, BA, Brasil.

\begin{abstract}
Objectives: To analyze the association between low birth weight (LBW) and the occurrence of the delay on the eruption of deciduous teething (DEDT) in children from 04 to 30 months, living in Salvador, Bahia.

Methods: A cross-sectional study involved 520 children at four to thirty months of age, from public, private and philanthropic daycares from two districts in Salvador. A descriptive analysis and unconditional logistic regression were done to estimate the odds ratios (ORs), using the Confidence Interval of $95 \%$ as a criterion for accepting associations. Poisson regression was used as an analytical strategy to obtain the prevalence ratio.

Results: the prevalence of the delay on the eruption was $10.29 \%$. There was a positive association between $L B W$ and occurrence of DEDT among children with less than 24 months, both in the unadjusted model $(P R=2.07,95 \% C I=0.964 .44)$ as in the adjusted (adjusted $P R=2,27,95 \% C I=1.025 .07)$.

Conclusions: the variables of development and nutritional at birth and during the early life may be important predictors of the chronology of eruption. Further investigations should be carried out towards the adequate evaluation of the $L B W$ role in the occurrence of the delay on the eruption.
\end{abstract}

Key words Tooth eruption, Deciduous tooth, low birth weight newborn, Epidemiology 


\section{Introduction}

Dental eruption understands all the movement of the tooth in the occlusal direction during the formation until it reaches its occlusal functional position with its antagonist. It constitutes the part of the physiological movements of the teeth relating to the maintenance of its position in the growing jaws and compensates by chewing decay and it is a useful assessment on the children's physiological and chronological age. 1-9 The knowledge on the normal timing of tooth eruption ranges from the intrauterine life up to 30 months, it has clinical relevance to diagnose various locations and systemic conditions that may affect this process. $1-2,4,6,9-17$

The variation in the chronological dental eruption is dependent of multiple genetic and environmental factors and none of them acts individually, there is an inter-relation among themselves during the development of deciduous teething, such as race, gender, systemic conditions, environmental conditions, socioeconomic level, maternal breastfeeding, infant nutritional status and physical development. 1,18

Nutritional factors influence the odontogenesis and the eruption of the teeth.16,17,19 During teeth development, the lack of nutrients such as calcium deficiency, 8 can affect not only the cellular architecture of the organic matrix, such as calcification and amelogenesis maturation process but also morphology and teeth eruption pattern.18,20 Other conditions as intrauterine growth restriction, inadequate size according to gestational age, exclusive parenteral nutrition for a long time can also potentially delay the eruption of deciduous teething. 8 In situations where prematurity and low birth weight (LBW) coexist in the delay of making it even greater, especially those who are at a critical stage of development at the moment of a systemic disorder and they are still unclassified at the moment of birth. $8,21,22$

There are evidence of a positive association between children with LBW and late teeth eruption related to an overall development delay.5,12,23 However, there are some controversies regarding the association between birth weight and time of the first tooth eruption. ${ }^{13}$ In some studies, when age is corrected for prematurity, there is no delay in the eruption. $12,22,24$

Thus, it is important to carry out studies on the chronology of the rupture of the first deciduous teething to analyze some factors that influence the delay of dental eruption. This study aims to analyze the association between LBW and the occurrence to delay the eruption of deciduous teething in children aged 04 to 30 months living in Salvador - BA.

\section{Methods}

A cross-sectional study was developed and the information used in this study were obtained from a preexisting database. A detailed description of the area and population of this study, the methods to select participants, procedures used in the data collection, the strategy and the criteria test, as well as the details on the ethical issues involved are presented in another publication. 25

This study tried to involve in the analysis all the participant children of the original research that adopted the census perspective $(\mathrm{n}=556)$. The group was composed of children four to thirty months of age attending public, private and philanthropic daycares in two districts in Salvador city (Barra-Rio Vermelho and Cabula - Beirú). On the opportunity, the exclusion criteria was considered finding congenital anomalies or systemic alterations that prevented the examination to be performed.

Delayed eruption was considered as a dependent variable. The chronology of the dental eruption was verified by registering the month of the first deciduous teething eruption. In this study, to define the delay of the eruption, Aktoren et al. 26 proposal was used to define delayed dental eruption. According to these authors, the children presented delayed eruption when his/her first tooth erupted after 40 weeks on the chronological age.

The main independent variable was low birth weight, considering if the child weighed less than $2500 \mathrm{~g}$ at birth, regardless of gestational age.

Among the socioeconomic and demographic covariates, the following were considered: the child's age in months; sex; skin color; family income; maternal schooling; maternal age, and the mother's marital status. Regarding to the variables, related to lifestyle, were considered as: breastfeeding pattern; time for maternal breastfeeding; the use of medication in the first months of the infant's life. Information regarding prenatal history was included in the analysis: pregnancy without complications, hypertension and urinary tract infection during pregnancy; alcohol, tobacco and drug consumption during pregancy and the performance of prenatal care. The variables related to childbirth were: gestational age; difficulty of suction; the use of catheter and the necessity of being intubated.

Initially, the descriptive analysis of the variables was performed, obtaining the simple frequencies for the categorical variables and the measures for the 
central tendency and dispersion for the continuous ones. The prevalence of effect was observed according to the covariates by analyzing the differences between the categories by using Pearson's Chi-square test.

Afterwards, the stratified analysis was performed to evaluate potential associations. In this phase, the crude associations between low birth weight and the delay in the chronology eruption were estimated, as well as for the covariates selected through the Prevalence Ratio and 95\% Confidence Intervals obtained by Mantel-Haenszel's Method. The modifying effect of the potential covariates were identified by verifying the difference in the prevalence ratio for each of its categories at a statistical significant level (alpha $=0.05)$. In the confounding covariates were observed whether they were simultaneously associated to the exposure among the non-cases and the outcomes among the non-exposed individuals, considering a relative difference between the adjusted measures of each covariate and the crude association measurement greater than $10 \%$ for the confounding identification. Along the elements of theoretical model and literature, this statistical procedure contributed to select covariates used in the modeling.

In multivariate analysis, the method used was unconditional logistic regression. For statistical inference the $95 \%$ Confidence Interval was used. The product terms were created to potentially modify the variables effect. The interaction analysis was performed through a backward modeling procedure, from the definition of the saturated or complete model and the reduced model for each potential modifier effect, observing the difference in the deviations between the saturated and the reduced models, and adopting an alpha $=0.20$ from the Maximum Likelihood- Ratio Test (MLRT) to verify statistical significance. The backward procedure in the confounding analysis was used, comparing the measurements of the association and its respective confidence intervals estimated for the saturated and reduced models.

The modeling procedures allowed the construction for the final model to estimate the odd ratios between low weight and the dependent variable controlled by the interaction variables and adjusted by the confounding variables. The Poisson Regression was used as an analytical strategy to obtain the Prevalence Ratio. The goodness of adjusting the model was verified by Hosmer and Lemeshow's Chi-square test. 27 The data were analyzed in the STATA7.0 program. 28

\section{Results}

Considering the original population of 556 children, it was observed that there was information regarding the eruption of the first tooth of 554 participants. On the other hand, proper birth weight registeration was available for 520 children. Thus, the population in this study was composed of 520 children ranging from four to thirty months of life and the mean age was 21.8 months, $\mathrm{SD}=6.82$. The prevalence of delayed eruption was $10.29 \%$, therefore, $89.71 \%$ of the children's eruption of their first tooth occurred before 40 weeks of the chronological age. The characteristics in the study population in relation to sociodemographic variables are according to the exposure shown in Table 1. Among the children with LBW, $14.71 \%$ had their first tooth erupted after 10 months. The prevalence among the same children were female, black/mixed ethnicity, family income of up to 01 minimum wage. For sociodemographic variables, the differences in proportion was according to birth weight that was not statistically significant.

In Table 2 the characteristics of maternal health and habits during pregnancy according to birth weight were observed. Statistically significant differences were observed for the occurrence of urinary tract infection during pregnancy $(p<0.001)$, smoking ( $p=0.016)$, the use of drugs during pregnancy $(p=0.009)$ and uneventful pregnancy $(0.017)$.

In regards to the covariables relating to childbirth and behavior, so this was verified, as expected, the statistical significant difference in the occurrence of prematurity according LBW $(p<0.001)$. Similarly, other variables intrinsically related to premature birth had higher ocorrence among low weight children as compared to others - born less than $50 \mathrm{~cm}$ long $(p<0.001)$, and have presented the necessity of hospitalization $(p=0.018)$, intubation $(p<0.001)$ and medications $(p<0.001)$ (Table 3$)$.

Bivariate analysis revealed a positive association, but without statistical significance between LBW and the delay of eruption $(\mathrm{PR}=1.51 ; 95 \%$ $\mathrm{CI}=0.79-2.86)$. Among the covariates selected for this analysis, only maternal schooling had a positive and statistically significant association to the outcome of this study, with higher occurrence of delayed eruption among children whose mothers had low schooling level $(\mathrm{PR}=1.91 ; 95 \% \mathrm{CI}=1.14-3.18)$ (Table 4 ).

The covariates did not behave as modifying or confounding effect in the stratified analysis. In the modeling, using the logistic regression method, the same result was observed. However, based on the 
Sociodemographic characteristics of the study population according to the presence of low birth weight, Salvador-BA, $2014(n=520)$.

\begin{tabular}{|c|c|c|c|c|c|}
\hline \multirow{3}{*}{ Covariables } & \multicolumn{4}{|c|}{ Low Birth Weight } & \multirow{3}{*}{$p^{1}$} \\
\hline & \multicolumn{2}{|c|}{$\begin{array}{l}\text { LBW absent } \\
\qquad(\mathrm{n}=452)\end{array}$} & \multicolumn{2}{|c|}{$\begin{array}{l}\text { LBW present } \\
\qquad(\mathrm{n}=68)\end{array}$} & \\
\hline & $\mathrm{n}$ & $\%$ & $\mathrm{n}$ & $\%$ & \\
\hline Delay in the eruption & & & & & 0.210 \\
\hline Absent & 408 & 90.17 & 58 & 85.29 & \\
\hline Present & 44 & 9.73 & 10 & 14.71 & \\
\hline Age & & & & & 0.357 \\
\hline$>24$ months & 186 & 41.15 & 32 & 47.06 & \\
\hline$\leq 24$ months & 266 & 58.85 & 36 & 52.64 & \\
\hline Sex & & & & & 0.116 \\
\hline Female & 213 & 47.12 & 39 & 57.35 & \\
\hline Male & 239 & 52.88 & 29 & 42.65 & \\
\hline Ethnicity & & & & & 0.105 \\
\hline White & 66 & 14.60 & 5 & 7.35 & \\
\hline Black / Mixed & 386 & 85.40 & 63 & 92.65 & \\
\hline Maternal schooling* & & & & & 0.939 \\
\hline High school or higher & 246 & 54.91 & 37 & 54.41 & \\
\hline Up to elementary level & 202 & 45.09 & 31 & 45.59 & \\
\hline Family income & & & & & 0.269 \\
\hline More than $1 \mathrm{MW}$ & 143 & 31.64 & 17 & 25 & \\
\hline Up to $1 \mathrm{MW}$ & 309 & 68.36 & 51 & 75 & \\
\hline Maternal age * & & & & & 0.684 \\
\hline 21 to 39 & 330 & 73.83 & 47 & 69.12 & \\
\hline$\leq 20$ & 108 & 24.16 & 19 & 27.94 & \\
\hline$\geq 40$ & 9 & 2.01 & 2 & 2.94 & \\
\hline Maternal marital status & & & & & 0.826 \\
\hline Married / Lives with a partner & 292 & 64.60 & 43 & 63.24 & \\
\hline Single / separated / widow & 160 & 35.40 & 25 & 36.76 & \\
\hline
\end{tabular}

*Missing data, 1= Mantel Haenszel's Chi-Square Test $p$ value, MW= Minimum Wage, LBW=Low Birth Weight. 
Table 2

Maternal health characteristics and gestational habits according to low birth weight, Salvador-BA, $2014(n=520)$.

\begin{tabular}{|c|c|c|c|c|c|}
\hline \multirow{3}{*}{ Covariables* } & \multicolumn{4}{|c|}{ Low Birth Weight } & \multirow{3}{*}{$p^{1}$} \\
\hline & \multicolumn{2}{|c|}{$\begin{array}{l}\text { LBW absent } \\
\qquad(n=452)\end{array}$} & \multicolumn{2}{|c|}{$\begin{array}{l}\text { LBW present } \\
\qquad(n=68)\end{array}$} & \\
\hline & $\mathrm{n}$ & $\%$ & $\mathrm{n}$ & $\%$ & \\
\hline Hypertension during pregnancy & & & & & 0.272 \\
\hline Absent & 413 & 92.19 & 60 & 88.24 & \\
\hline Present & 35 & 7.81 & 8 & 11.76 & \\
\hline Urinary tract infection during pregnancy & & & & & 0.001 \\
\hline Absent & 416 & 92.86 & 55 & 80.88 & \\
\hline Present & 32 & 7.14 & 13 & 19.12 & \\
\hline Smoking during pregnancy & & & & & 0.016 \\
\hline Absent & 414 & 92.62 & 57 & 83.82 & \\
\hline Present & 33 & 7.38 & 11 & 16.18 & \\
\hline Alcohol consumption uring pregnancy & & & & & 0.155 \\
\hline No & 426 & 95.30 & 62 & 91.18 & \\
\hline Yes & 21 & 4.70 & 6 & 8.82 & \\
\hline Use of drug during pregnancy & & & & & 0.009 \\
\hline No & 403 & 90.16 & 54 & 79.41 & \\
\hline Yes & 44 & 9.84 & 14 & 20.59 & \\
\hline Uneventful pregnancy & & & & & 0.017 \\
\hline Yes & 338 & 75.45 & 42 & 61.76 & \\
\hline No & 110 & 24.55 & 26 & 38.24 & \\
\hline Prenatal care & & & & & 0.861 \\
\hline Yes & 404 & 90.38 & 61 & 89.71 & \\
\hline No & 43 & 9.62 & 7 & 10.29 & \\
\hline
\end{tabular}

1Mantel Haenszel's Chi-Square Test $p$-value, *There were missing data in all the variables, LBW=Low Birth Weight. 
Birth and behavioral characteristics of the study population according to the presence of low birth weight, SalvadorBA, $2014(n=520)$.

\begin{tabular}{|c|c|c|c|c|c|}
\hline \multirow{3}{*}{ Covariables } & \multicolumn{4}{|c|}{ Low Birth Weight } & \multirow{3}{*}{$p^{1}$} \\
\hline & \multicolumn{2}{|c|}{$\begin{array}{l}\text { LBW absent } \\
\qquad(n=452)\end{array}$} & \multicolumn{2}{|c|}{$\begin{array}{l}\text { LBW present } \\
(n=68)\end{array}$} & \\
\hline & $\mathrm{n}$ & $\%$ & $\mathrm{n}$ & $\%$ & \\
\hline Prematurity & & & & & $<0.001$ \\
\hline Absent & 431 & 95.35 & 39 & 57.35 & \\
\hline Present & 21 & 4.65 & 29 & 42.5 & \\
\hline Height at birth * & & & & & $<0.001$ \\
\hline$\geq 50 \mathrm{~cm}$ & 154 & 45.56 & 3 & 5.88 & \\
\hline$\leq 50 \mathrm{~cm}$ & 184 & 54.44 & 48 & 94.12 & \\
\hline Need of hospitalization at childbirth & & & & & 0.018 \\
\hline No & 389 & 86.06 & 51 & 75.00 & \\
\hline Yes & 63 & 13.94 & 17 & 25.00 & \\
\hline Use of Probe & & & & & $<0.001$ \\
\hline No & 447 & 98.89 & 61 & 89.71 & \\
\hline Yes & 5 & 1.11 & 7 & 1.29 & \\
\hline Need to be intubated & & & & & 0860 \\
\hline No & 444 & 98.23 & 67 & 98.53 & \\
\hline Yes & 8 & 1.77 & 1 & 1.47 & \\
\hline Breastfeeding & & & & & 0.304 \\
\hline Yes & 393 & 86.95 & 56 & 82.35 & \\
\hline No & 59 & 13.05 & 12 & 17.65 & \\
\hline Breastfeeding duration (months) & & & & & 0.835 \\
\hline More than or equal to 6 & 152 & 33.63 & 22 & 32.35 & \\
\hline Less than 6 & 300 & 66.37 & 46 & 67.65 & \\
\hline Artificial feeding & & & & & 0.822 \\
\hline No & 127 & 28.10 & 20 & 29.41 & \\
\hline Yes & 325 & 71.90 & 48 & 70.59 & \\
\hline Use of medication & & & & & $<0.001$ \\
\hline No & 418 & 92.48 & 53 & 77.94 & \\
\hline Yes & 34 & 7.52 & 15 & 22.06 & \\
\hline
\end{tabular}

*Missing data, ${ }^{*}=$ Mantel Haenszel's Chi-Square Test $p$ - value, LBW=Low Birth Weight. 


\section{Table 4}

Prevalence and Prevalence Ratios and Confidence Intervals at $95 \%$ of the crude association between the analyzed covariates and the delayed eruption, Salvador-BA, $2014(n=520)$.

\begin{tabular}{|c|c|c|c|c|c|}
\hline Variables & $\mathbf{N}$ & $\%$ & $\mathbf{R P} \mathbf{1}$ & $\mathrm{Cl} 95 \%{ }^{2}$ & $p^{3}$ \\
\hline Low birth weight & & & & $0.79-2.86$ & 0.21 \\
\hline No & 44 & 9.73 & 1.00 & & \\
\hline Yes & 10 & 14.71 & 1.51 & & \\
\hline Age & & & & $0.61-1.67$ & 0.96 \\
\hline 24 months or more & 24 & 1.21 & 1.00 & & \\
\hline Less than 24 months & 33 & 10.34 & 1.01 & & \\
\hline Skin color & & & & $0.65-3.82$ & 0.29 \\
\hline White & 5 & 6.86 & 1.00 & & \\
\hline Black / Mixed & 52 & 1.81 & 1.58 & & \\
\hline Sex & & & & $0.83-2.24$ & 0.22 \\
\hline Male & 25 & 8.74 & 1.00 & & \\
\hline Female & 32 & 11.94 & 1.37 & & \\
\hline Maternal schooling* & & & & $1.14-3.18$ & 0.01 \\
\hline High school or higher & 21 & 7.27 & 1.00 & & \\
\hline Elementary level or less & 36 & 13.85 & 1.90 & & \\
\hline Uneventful Pregnancy * & & & & $0.45-1.48$ & 0.51 \\
\hline Yes & 44 & 10.92 & 1.00 & & \\
\hline No & 13 & 8.97 & 0.82 & & \\
\hline Gestational age & & & & $0.62-2.71$ & 0.49 \\
\hline At term & 50 & 10.02 & 1.00 & & \\
\hline Premature & 7 & 12.96 & 1.29 & & \\
\hline Exclusive breastfeeding & & & & $0.65-2.36$ & 0.51 \\
\hline Yes & 47 & 9.94 & 1.00 & & \\
\hline No & 10 & 12.35 & 1.24 & & \\
\hline Breastfeeding duration & & & & $0.68-2.01$ & 0.57 \\
\hline 6 months or more & 17 & 9.24 & 1.00 & & \\
\hline Less than 6 months & 40 & 10.81 & 1.17 & & \\
\hline
\end{tabular}

*Missing data, 1= Prevalence Ratio, $295 \%$ Confidence Interval, 3= Mantel Haenszel's Chi-Square Test $p$-value.

Table 5

Estimates of crude and adjusted PR and the respective $95 \%$ Confidence Intervals for the association between low birth weight and the delayed eruption according to age obtained by the logistic regression, Salvador-BA, 2014 ( $n=520$ ).

\begin{tabular}{|c|c|c|c|c|}
\hline \multirow{3}{*}{ Delay in eruption } & \multicolumn{4}{|c|}{ Child's age } \\
\hline & \multicolumn{2}{|c|}{$\begin{array}{l}\text { More than } 24 \text { months } \\
\qquad(n=218)\end{array}$} & \multicolumn{2}{|c|}{$\begin{array}{l}\text { Up to } 24 \text { months } \\
\qquad(n=302)\end{array}$} \\
\hline & RP1 & $\mathrm{Cl} 95 \% 2$ & $\mathbf{R P 1}$ & $\mathrm{Cl} 95 \% 2$ \\
\hline \multicolumn{5}{|l|}{ Model 1 (delayed eruption) } \\
\hline Present & 0,92 & $0,29-2,93$ & 2,07 & $0,96-4,44$ \\
\hline \multicolumn{5}{|l|}{$\begin{array}{l}\text { Model } 2 \text { (delayed, adjusted for uneventful } \\
\text { pregnancy and breastfeeding) }\end{array}$} \\
\hline Present & 0,89 & $0,28-2,82$ & 2,27 & $1,02-5,07$ \\
\hline
\end{tabular}

$1=$ Prevalence Ratio, 2= 95\% Confidence Interval. 
literature, the final model was controlled by the covariate of the child's age and to measure the crude and adjusted association to the exclusive breastfeeding and pregnancy without complications were generated. Thus, there was a positive association between LBW and the delayed eruption in children younger than 24 months (PR adjusted $=2.27,95 \%$ $\mathrm{CI}=1.02-5.07$ ) (Table 5).

The diagnoses performed for the logistic models adjusted in Strata (age $=0$ and age $=1$ ), respectively, using the Hosmer and Lemeshow's Chi-square test ( $p=0,842$ and $p=0,067$ ), the area under the ROC curve, 0.59 and 0.55 , which showed acceptable discrimination between the delays (1) and nondelays (0) in relation to LBW (exposure), in addition to the model agreement, $89.8 \%$ and 89.3 , high specificity, $100 \%$ and $100 \%$, and the influential covariate patterns indicated that the models would adjust to the data.

\section{Discussion}

The results suggest that in the studied population, there is an association between LBW and the occurrence of delayed eruption in children under 24 months of age. After adjusting for the independent variables which were exclusive breastfeeding and uneventful pregnancy, there was an increase in the strength of this association that became statistically significant.

Considering the measures of occurrence of late dental eruption (LDE) observed in this study, it can be mentioned that the overall prevalence $(10.29 \%)$, and the prevalence found among children with LBW (14.71\%) are less when comparing to the results of other studies involving the same age group. Aktoren et al. 26 , for example, verified that $21.95 \%$ of the premature children studied had their first tooth erupted after 10 months of age.

This study reinforces the hypothesis that biological and nutritional factors present in the "early" life influence dental eruption patterns later in life. Specifically, the effects of intrauterine growth and nutritional status may be seen on deciduous teething. It was observed that children with LBW had higher occurrence of LDE, which this agrees with Rezende et al. 16 study that children who were born with low weight had a late dental eruption compared to children who had birth weight greater than $2,500 \mathrm{~g}$. According to Andrade et al. ${ }^{23}$, dental eruption is a sign of development most affected by the variables that were most often described as acting on the child's integral evolution. Thus, among underweight, premature, malnourished children who are not breastfeeding or were not breastfed at any time in their lives, children of teenage mothers whose schooling did not pass the fourth grade in the elementary level showed a significant risk of delayed teething compared to children who did not have any of these conditions.

Ramos et al. 12 also found a positive statistically significant association between birth weight and the timing of the first tooth eruption by using the chronological age, as this study did.

According to these authors, children whose birth weight was less than $1,500 \mathrm{~g}$ had their first tooth erupted later when compared to those whose birth weight was between 1,500 and $2,499 \mathrm{~g}$ and those whose birth weight was $2,500 \mathrm{~g}$ or more. However, when the corrected age was used, there was no statistically significant difference in the three birth weight groups.

In Sjjadian et al.13 work on linear regression analysis, identified a negative linear correlation between birth weight and the first deciduous teething eruption. This result suggests that nutritional and developmental variables at birth and through early life may be important predictors of the chronological eruption of the first deciduous teething.

Al-Sayagh et al.21 observed delayed eruption of deciduous teething in children with LBW in relation to children in the control group in all age groups except for the 4 to 6 months group. When comparing the mean age of the eruption between normal-weight and low-weight infants, Um et al. ${ }^{4}$ had checked that the same occurred significantly earlier in children born with normal weight, with an exception of the maxillary first molar and the upper and lower canine teeth.

This presente study highlights the approach of the variables potentially associated with prematurity and uneventful pregnancy (tobacco use, urinary tract infection and others). Thus, it reinforces the hypothesis that children presenting malnutrition before childbirth, during which the teeth are still being formed, they suffer a nutritional problem in which can cause damage in the development of deciduous teething. ${ }^{1}$ As LBW may be due to intrauterine growth restriction, which is a condition related to inadequate nutrition, it may alter the magnitude of the delayed eruption of the deciduous teething. ${ }^{24,29}$

Unlike the present study, Um et al. ${ }^{4}$ did not find any statistically significant correlation between the timing of eruption of the deciduous teething and birth weight. The results point to the fact that the baby, even those born prematurely or underweight, may present at any age, as many erupted teeth as full-term and normal weight babies as long as their 
growth has reached a an accelerated pace to the point where his/her height and age appropriate represents a higher percentile than those with normal anthropometric measurements at birth.

Alnemer et al. 10 results showed a distinct relation between birth weight and the number of erupted teeth. According to the authors, LDE is common in premature babies regarding to deciduous teething, but the catch-up development occurs after early childhood and regularizes the chronological eruption.

Delayed dental development in premature children has also been researched by Zaidi et al. ${ }^{24}$ who identified this as a LDE cause. This study observed that prematurity was an important adjusted variable in the modeling, because in some studies showed a delay in the dental eruption among premature children, but when the corrected age was considered, no delay was found in the chronological eruption. $8,10,29$ The corrected age is the postnatal age subtracted of the number of days, weeks or months to complete 40 weeks at the time of the child's birth. 29

Alnemer et al. 10 could demonstrate the lower the birth weight, the longer the delay in the dental eruption. However, they stated that when the corrected age was considered, there was no difference between the groups, implying that the delayed eruption among low birth weight children was simply attributed to their premature birth. Thus, LBW may lead to a delayed dental eruption due to prematurity rather than the delayed dental development. 29

In this study, the confounding and interaction analysis did not reveal the necessity to adjust or control the researched covariates. However, it is known that children with LBW typically tend to regain growth velocity between 2 and 3 years of age, during the recovering growth phase or the catch-up phase. This phase is characterized by a rapid increase on the weight, length and head circumference with an accelerated growth rate, surpassing children found in the general population of full-term and normal birth weight. The catch-up weight growth is the compensatory weight gain and above normal standards for specific age between birth and 24 months. Considering the catch up and the delay in the dental eruption in children with low birth weight is even more evident until 24 months of age, 11,29 opting to control the child's covariate age, even if the child did not behave as a modifier effect in the analysis. Higher magnitude of positive associations were found among children aged up to 24 months.
As the delays in the eruption of the deciduous teething are common in children who were not breastfed by mothers 1 and considering that the existence of uneventful pregnancy is an important predictor in a child's health and adjusted models were generated for uneventful pregnancy and for exclusive breastfeeding.

Birth weight results from prenatal growth and dental eruption is cumulatively influenced by both prenatal and postnatal growth, as well as the genetic, maternal and gestational factors. ${ }^{4}$ The presence of uneventful pregnancy, such as maternal diseases, the use of medication, smoking, alcohol and other drugs can influence the time of the dental eruption, either through the occurrence of premature birth, inadequate birth weight or both, this has been analyzed in this manuscript. As LBW may be related to lower gestational age, lower weight and systemic problems, children who are born under this condition tend to have a delayed eruption of their first deciduous teething. 24,29

Some methodological aspects need to be discussed. It should be noted that epidemiological approaches of confirmatory character and that consider the multiple factors involved in a determined investigated effect are rare in the epidemiology field of alterated eruptions, where most studies employ bivariate or descriptive analyzes. However, it should be considered that the cross-sectional study design and its limits for the causal hypothesis test were in exposure and the effects are investigated at the same moment. Although, in this study, the exposure (LBW) is necessarily prior to teething eruption, thus, there may have been a memory bias in relation to this variable.

In spite of the limitations, this study suggests that the development and nutritional variables at birth and during early life may be important predictors for the children's first deciduous teething eruption time in their early childhood.

\section{Authors' Contributions:}

Castro CRS, Vianna MIP, Cabral MBBS e Mota ELA - elaboration of the article, analysis and interpretation of the data, writing the draft manuscript, critical revision of the content and elaboration of the final version of the manuscript. Cangussu MCT writing the draft manuscript, critical review of the content and preparation of the final version of the manuscript. All authors approved the final version of the manuscript. 


\section{References}

1. Duarte MEQ, Andrade MA, Faria PC, Marques LS, Jorge MLR. Fatores associados à cronologia de erupção de dentes decíduos - revisão de literatura: erupção de dentes decíduos e fatores associados. Rev Uni Vale do Rio Verde. 2011; 9 (1): 139-51.

2. Caregnato M, Mello LD, Silveira EG. Estudo da cronologia da erupção dental decídua das crianças atendidas nas clínicas do curso de Odontologia da Univali. Rev Sul-Bras Odontol. 2009; 6 (3): 237-42.

3. Brandão $\mathrm{CF}$, Rocha $\mathrm{MC}$. Cronologia e sequência de erupção dos dentes decíduos em crianças de 0 a 42 meses. JBP Rev Ibero-am Odontopediatr Odontol Bebê. 2004; 7 : 528-35.

4. Um L, Hsu CS, Yee R, Koh D, Lee YS, Chong MF, Cai M, Kwek K, Saw SM, Godfrey K, Gluckman P, Chong YS. Influenceofmetabolic linked early life factors on the eruption timing of the first primary tooth. Clin Oral Investig. 2016; 20 (8): 1871-9.

5. Bastos JL, Peres MA, Peres KG, Barros AJ. Infant growth, development and tooth emergence patterns: a longitudina study from birth to 6 years of age. Arch Oral Biol. 2007; 52 (6): 598-606

6. Suri L, Gagari E, Vastardis H. Delayed tooth eruption: Pathogenesis, diagnosis, and treatment. A literature review. Am J Orthod Dentofacial Orthop. 2004; 126 (4): 432-45.

7. Pavicin IS, Dumancic J, Badel T, Vodanovic M. Timing of emergence of the first primary tooth in preterm and fullterm infants. Ann Anat. 2016; 203: 19-23.

8. Fernandes Neto PG, Falcão MC. Cronologia de erupção dos primeiros dentes decíduos em crianças nascidas prematuras com peso inferior a 1500g. Rev Paul Pediatr. 2014; 32 (1): $17-23$.

9. Woodroffe S, Mihailidis S, Hughes T, Bockmann M, Seow WK, Gotjamanos T, Townsend G. Primary tooth emergence in Australian children: timing, sequence and patterns of asymmetry. Aust Dent J. 2010; 55: 245-51

10. Alnemer KA, Pani SC, Atthubaiti AM, Bawazzer M. Impact of birth characteristics, breastfeeding and vital statistics on the eruption of primary teeth among health infants in Saudi Arabia: an observational study. BMJ Open. 2017; 7 (12): e018621.

11. Gunashekhar M, Tenny J. Longitudinal study of age and order of eruption of primary teeth in Indian children. J Clin Exp Dent. 2010; 3 (2); 113-6.

12. Ramos SRP, Gugisch RC, Fraiz FC. The influence of gestacional age and birth weight of the newborn on tooth eruption. J Appl Oral Sci. 2006; 14 (4): 228-32.

13. Sajjadian N. Shajari H, Jahadi R, Barakat MG, Sajjadian A Relationship between birth weight and time of first deciduous tooth eruption in 143 consecutively born infants Pediatr Neonatol. 2010; 51 (4): 235-7.

14. Casanova-Rosado AJ, Sánchez MM, Casanova-Rosado JF, Santilana RDR, Ramirez ME, Ruiz VO, Solis CEM.
Impacto de laposición socioeconómica sobre losdefectos de desarrollodel esmalte endentición primaria. Rev CES Odont. 2012; 25 (1): 22-31.

15. Verma N, Bansal A, Tyagi P, Jain A, Tiwary V, Gupta R. Eruption chronology in children: a cross sectional study. Int J Clin Pediatr Dent. 2017; 10 (3): 278-82.

16. Rezende KMPC, Zöllner MSAC, Santos MRN. Avaliação da Erupção Dental Decídua em Bebês Considerados de Risco. PesqBrasOdontopedClin Integr. 2010; 10 (1): 61-5.

17. Vantine FF, Carvalho PL, Candelária LFA. Estudo dos fatores que alteram a cronologia de erupção dentária. Rev Bras Epidemiol. 2010; 13 (2): 246-58.

18. Lynch RJ. The primary and mixed dentition, pos- eruptive enamel maturation and dental caries: a review. Int Dent J. 2013; 63 (Suppl. 2): 3-13.

19. Thomaz EB, Alves CM, Ribeiro CC, Batista RF, Simões VM, Cavalli R, Rasaiva MDAC, Cardoso VC, Bettiol H, Barbieri MA, da Silva AA. Perinatal outcomes and changes in the oral cavity: Brazilian cohorts of Ribeirão Preto and São Luis. Rev Bras Epidemiol. 2015; 18 (4): 966-70.

20. Peedikayil FC. Delayed tooth eruption. e-Journal of Dentistry. 2011; 1 (4): 81-6.

21. Al-Sayagh GD, Qasim AA, Al-Rawi BA. The effect of premature birth on the primary dentition. Al-Rafidain Dent J. $2008 ; 8$ (1): 18-22.

22. Zaidi I, Tahyath MN, Singh S, Sinha A. Preterm birth: a primary etiological factor for delayed oral growth and development. Int J Clin Pediatric Dent. 2015; 8 (3): 215-9.

23. Andrade KC, Souza SB, Szarfarc SC. Desenvolvimento neuromotor e dentição de crianças atendidas em serviços públicos de saúde do Brasil, no primeiro ano de vida. Rev Bras Crescimento Desenvolv Hum. 2007; 17 (2): 37-44.

24. Ferrini FRO, Marba STM, Gavião MB. Alterações bucais em crianças prematuras e com baixo peso ao nascer. Rev Paul Pediatr. 2007; 25 (1); 66-71.

25. Cabral MBBS, Mota ELA, Cangussu MCT, Vianna MIP, Floriano FR. Risk factors for caries-free time: longitudinal study in early childhood. Rev Saúde Pública. 2017; 51 (118): $1-12$

26. Aktoren O, Tuna EB, Guven Y, Gokcay G. A study on neonatal factors and eruption time of primary teeth. Community Dent Health. 2010; 27 (1): 52-6.

27. Hosmer DW, Lemeshow S. A goodness-of- fit test for the multiple logist regression model. Communications in Statistics. 1980; A10: 1043-69.

28. Stata Corporation, 1997. Stata Reference Manual Release 7. College Station: Stata Corporation.

29. Paulsson L, Bondemark L, Soderfeldt B.A Systematic Review of the Consequences of Premature Birth on Palatal Morphology, Dental Occlusion, Tooth-Crown, Dimensions, and Tooth Maturity and Eruption. Angle Orthodontist. 2004; 74 (2): 269-79.

Received on January 22, 2018

Final version presented on September 21, 2018

Approved on July 25, 2019 